\title{
Food Security and Nutrition among Adults Living with Disability in Nakuru County, Kenya
}

\author{
Peter M Chege ${ }^{1 *}$, Grace W Gachuiri ${ }^{2}$ and Zipporah W Ndungu ${ }^{3}$ \\ ${ }^{1}$ Department of Food, Nutrition and Dietetics, Kenyatta University, GPO Nairobi, Kenya \\ ${ }^{2}$ Department of Nursing, Kenyatta University, GPO Nairobi, Kenya \\ ${ }^{3}$ Department of Food, Science and Technology, Jomo Kenyatta University of Agriculture and Technology, Juja, Kenya
}

*Corresponding author: Peter Chege, Department of Food, Nutrition and Dietetics, Kenyatta University, Kenya, E-mail: chegepeterm@gmail.com

Received: 17 Jun, 2019 | Accepted: 15 Jul, 2019 | Published: 22 Jul, 2019

Citation: Chege PM, Gachuiri GW, Ndungu ZW (2019) Food Security and Nutrition among Adults Living with Disability in Nakuru County, Kenya. Nutr Food Technol Open Access 5(1): dx.doi.org/10.16966/2470-6086.157

Copyright: (C) 2019 Chege PM, et al. This is an open-access article distributed under the terms of the Creative Commons Attribution License, which permits unrestricted use, distribution, and reproduction in any medium, provided the original author and source are credited.

\begin{abstract}
People living with disability (PLD) are among the most vulnerable groups to health and nutrition problems mainly due to limited access to essential services. Minimal information exists on food security and nutrition status among PLD as they are normally excluded from many researches due to challenges in conducting assessments. This study aimed to document the food security and nutrition status. The study adopted a cross-sectional analytical research design, in Nakuru municipality, Nakuru County on a randomly selected sample of 422 adults living with various forms of disability. Data was collected using a semi-structured questionnaire. Quantitative data was analyzed using SPSS. Physical disability (67.2\%) was the main disability problem, followed by mental disability $(15.2 \%)$, deafness/dumbness $(10.9 \%)$ and visual impairment (5.1\%). Over $68 \%$ were dependent on other people for movement and accessibility to essential services. Most of the PLD (55.5\%) earned an income of <100 USD monthly, leading to about $40 \%$ being food insecure. Prevalence of hypertension, diabetes and cardio-vascular diseases was $25.8 \%, 5.5 \%$ and $6.3 \%$, respectively. The prevalence of overweight, obesity and underweight was $21.5 \%, 10.2 \%$ and $23.4 \%$, respectively, a clear indication of dual burden of malnutrition. Over a half (53.9\%) were noted to be living with stigma towards disability. Among PLD, food insecurity and poor nutrition status is a common phenomenon. There exists a dual burden of malnutrition. There is thus need to train PLD on good nutrition and on entrepreneurship for income generation.
\end{abstract}

Keywords: People living with disability; Food security; Nutrition status; Adults

\section{Introduction}

According to World Health Organization (WHO) [1], disability is defined as any restriction or lack of ability to perform an activity in the manner or within the range considered normal for a human being. Disability is the loss or limitation of opportunities to take part in the normal life of the community on an equal level with others due to physical and social barriers. Disability can be inborn or can result from communicable diseases and injuries [2]. Some form of the disability could be eliminated through vaccinations, treatment or rehabilitation.

The World Health Organization states that disability affects $10 \%$ of population. It is estimated that 650 million people worldwide are living with disability. In Kenya, at least $4.6 \%$ of the population has a form of disability [3]. A study by KNSPWD indicated that $15 \%$ of people with disabilities are affected by environmental factors on a daily basis while $65 \%$ highlighted the environment as a major problem in their daily lives.

Social discrimination of the physically disabled persons has not made it easier for them to cope with their limitations. Challenges such as discrimination have led to some living in the backyard. Viewing disability as a curse in the society makes them feel as if they do not belong to our society. Most people view the disabled as burdensome people [4]. In addition, majority do not access health, environmental and economic resources [5,6]. Most need special education which is not well structured in the current education system. The community lack awareness about the disabled people. Social support by the society would go a long way in helping cope with their conditions. Individuals living with disabilities are faced with structural barriers like institutional misunderstanding and employer misunderstanding [7].

People living with disability (PLD) often do not benefit from the same level of services as the other members of the society who are non-disabled [8]. Most of them are unable to engage in agricultural activities due to physical challenges [9]. This has prompted a good number of the disabled people to live and earn their living through begging from the streets of major commercial towns due to lack of employment [10].

The KNSWPWD reported that a third of the PWDs' worked on own family business with a quarter doing no work. Only $16 \%$ worked for a pay and 1 out of 10 were reported to be homemakers. About $80 \%$ 
of the world's persons with disabilities live in low income countries where they are socially and economically disadvantaged [1]. Disability affects accessibility and participation in economic and social activities. Disabled persons are more likely to be unemployed and earn less when employed, employment and income worsen with severity of disability [11]. Inaccessibility to economic and social rights affects the disability in accessing food and engaging in food production.

People living with disabilities are the most disadvantaged in the society especially in the job industry. They are usually isolated from the rest of the working community. The society believes that disability is the dilemma of someone else. Many employers opt to employ more able personnel with the perception that people with disabilities will perform inferior as compared with their counterparts. This is not the case as people with disabilities go beyond to find the means to meet the challenges that may arise where in most instances the solution frequently isn't ideal. Individual with disabilities may not have the productivity capability as able persons, but they stretch their limit thriving to achieve the same production efficiency in the work place [12].

Disability accounts for about $20 \%$ of the world's poorest and most vulnerable individuals who are almost always twice disadvantaged, especially in terms of food access when faced with risks like climatic change. Food accessibility is one of the dimensions of food security. Accessibility of food is complex and entails location to access food, resource mobilization especially finance and transportation as well as appropriate cognitive ability to plan and carry out activity of accessing food. Older adults and adults with disability have been suggested to have more difficulty in accessing food because of physical limitations. Food accessibility is important in an individual's life hence considerations are needed especially on how PLD will access food. Research has suggested more studies especially on how growing population with mobility disability can access food better [13]. A study by Brucker DL, et al. [14] in United States noted that disability was significantly associated with poverty.

A study in Kenya shows that disabled cannot engage adequately in food production, hence they account for $28 \%$ of individuals receiving relief food, especially at age of 60 and above. A research noted that people living with disabilities are neglected in many parts of Kenya, especially in empowerment opportunities, denying them a chance to participate fully in boosting food production [9]. A study in US found disability to relate to food insecurity [15]. Similarly a study in focusing on sub Saharan Africa by Quarmby CA and Pillay M [16] also noted association of disability and food insecurity.

Employment discrimination has been suggested to be among challenges facing individuals with disabilities revolving around issues like reasonable accommodation, termination and work place retaliation [10]. People with disabilities have been suggested to face disadvantages ranging from social to environmental determinants of health like unemployment and lower levels of education. In addition, disability has been linked to poverty, poor access to health care, poor nutrition, inadequate basic needs, hence overall poor health status [6].

Lack of employment predispose PLD to food insecurity and finally to malnutrition [13]. Poor dietary practices has been reported among disabled people with a study among US adults reporting that people with disability are less likely to follow guidelines on saturated fat, fiber, vitamin $\mathrm{A}$, vitamin $\mathrm{C}$, calcium and potassium [2]. Disability affects nutritional status especially where assisted feeding is required coupled with neglect within the household to care for disabled family members.

\section{Problem Statement}

People living with disability are part of human life despite the condition. Discrimination in various aspects of life as well as research has exposed them to a lot of life challenges, with some not reaching the optimal life. These challenges include malnutrition, high morbidity and presence of lifestyle diseases. Due to this, only a few interventions are targeted towards them, especially due to lack of adequate information. The new constitution has defined ways of inclusion of PLD in various sectors. Lack of adequate information on this marginalized group hampers these efforts.

In many researches that have been done, the PLD are always considered as exclusion criteria in studies [17]. The occupational challenges, stigma and low rates of employment compound the problem. Due to immobility and poor exercise, they are exposed to overweight and obesity. Research has suggested that the existence of poor standards of measurement of disability is a challenge in many studies [18]. People with disabilities have also been excluded in many opportunities especially because of the limited functionality and participation. The aim of this research was to assess food security and nutrition status among adults living with disability in Nakuru County, Kenya. This study asses the hypothesis that food security is related to the income and nutrition status of PLD.

\section{Methods}

The study adopted a cross-sectional analytical study design. The design is justified as it allow for testing of hypotheses and comparison of variables. This research was done in Nakuru town in Nakuru County. The area was purposively selected as one of the urban centers with a cosmopolitan population and being one of the towns with a high number of PLD [3]. Kenyans in urban areas mainly depend on food procurements as opposed to food production. PLD prefer towns where they can be employed rather than living in rural areas, as undertaking agricultural activities is a challenge [3].

This research targeted all adults living with all forms of disability (18-59 years old). Those who decline to consent to the study were excluded from the study. All the PLD who were chronically ill as established from medical records were excluded from the study.

Fisher formula was used for the determination of the sample size $[19,20]$ giving a sample of 384 respondents. To cater for the nonresponse cases, $10 \%$ of the sample size was added to come up with the final sample size for the study as 422 .

Through the help of the organizations that deals with the disabled in the town, key informants, faith based organizations and community health workers; a listing of all the PLD was compiled. This is to capture all the PLD including those that do not come to the open. Cluster sampling was used to group the population into the various forms of disability. Proportionate to size sampling was used to get the sample size in each cluster. The regions in Nakuru town were clustered to ensure that all areas are included. The population was distributed to these regions. In each cluster systematic random sampling was used to select participants. A comprehensive sample was adopted where cases affected by a certain form of disability were less than the calculated sample size. If in a household there were more than one PLD, random sampling was used to select one.

Data was collected using a semi-structured questionnaire, focus group discussion guides and key informants. Five focus group discussion guides were conducted among the groups of various categories of disability. This includes one on caretakers and four on PLD categorized into various age and gender categories. The 
questionnaire was pre-tested on $10 \%$ of the sample size giving 42 PLD.

The study participants were recruited to respond to the various questions. For the deaf and mentally retarded, the caretaker responded to the questions. Each of the five FGDs had 10 PLD and was conducted for one hour. The responses were recorded using a digital voice recorder. Dietary practices were assessed using a 24 hour recall for the previous day from the time they woke up to the time they slept and was recorded. Food Frequency Questionnaire (FFQ) was used to the frequency of the foods taken.

The weight was taken on minimum clothing using a weighing scale calibrated to zero and recorded to the nearest $0.1 \mathrm{~kg}$. This process was repeated twice and an average calculated. The height was measured using a stadiometer where the PLD stood on a flat surface without shoes and head gears as much as culturally acceptable and recorded to the nearest $0.1 \mathrm{~cm}$ and repeated twice and an average taken. Food security was assessed using Dietary Diversity Score (DDS). Data from 24 hour recall and food frequency was analyzed using the Nutrisurvey software. For DDS a score of $<4$ was considered as low dietary diversity and of $>4$ was considered as high dietary diversity [20]. Recommended Daily Allowances (RDA) for energy was compared with references provided by $\mathrm{FAO} / \mathrm{WHO}$ [21]. Anthropometric data was analyzed using a BMI calculator. All the data were cleaned and entered (double entry) using the CsPro computer software for accuracy. The data was exported to SPSS version 20.0 for analysis. Frequencies and percentages were used to describe the data. Pearson co-relation (r) was used to assess the hypothesis that food security is related to the income and nutrition status of PLD.

\section{Results}

Out of the targeted 422 participants, sample of 396 completed the study.

\section{Demographic and Socio-economic Characteristics of PLD}

Results show that most of the respondents (32.6\%) were between the ages of 30-39 years. Most of the PLD (52.3\%) engaged in small business with majority (55.5\%) earning a monthly income of $<100$ USD per month (Table 1). This was mainly as a result of most of them not being employed in the formal sector. Over $68 \%$ were dependent on other people for movement and accessibility to essential services. This was mainly due to the fact that most of the public facilities were not customized to accommodate PLD.

\section{Various Forms of Disability}

Physical disability (67.2\%) was the main disability problem, followed by mental disability (15.2\%), deafness/dumbness (10.9\%) and visual impairment (5.1\%). Over 68\% were dependent on other people for movement and accessibility to essential services (Figure 1).

\section{Dietary diversity}

About $68.8 \%$ of the PLD were food insecure as given by consumption of less than four food groups per day. This is attributed to low income. A majority (14.1\%) did not meet their daily energy requirements due to food insecurity. Some were noted to have low intake while others had excessive intake of energy, which led to underweight as well as overweight and obesity respectively (Table 2).

\section{Nutrition status among PLD}

The prevalence of overweight, obesity and underweight $21.5 \%$, $10.2 \%$ and $23.4 \%$, respectively, which is a clear indication of dual burden of malnutrition (Figure 2).

\section{Relationship between dietary diversity score and nutrition} status

This study notes a positive significant relationship between DDS with income $(\mathrm{r}=0.63, \mathrm{p}=0.021)$ and nutrition status $(\mathrm{r}=0.72, \mathrm{p}=0.018)$ (Table 3).

\section{Discussion}

Since majority were not employed, the income was low. This is a contributing factor to procurement of low quality foods. This agrees with a study by Vick A and Lightman E [7] and Snyder LS, et al. [4] that found out that there exist barriers to employment among PLD. Most of the PLD (55.5\%) earned an income of $<100$ USD monthly. A study by Palmer M [6] associated disability and poverty. This agrees with results from a study by Brucker DL, et al. [14] in United States noted that disability was significantly associated with poverty, where PLD lived in low socio-economic status. Physical disability (67.2\%) was the main disability problem, just like a study by Bjelland MJ, et al. [10] notes physical disability forming more proportion of PLD.

About $68.8 \%$ of the PLD were food insecure as given by consumption of less than four food groups per day which is in agreement with a study by Huang DL, et al. [13] where PLD could not access quality food. The study noted a significant relationship between food security with income and nutrition status. A study in the US found disability to be an important risk factor for food insecurity [15]. Similarly a study in focusing on sub Saharan Africa by Quarmby CA and Pillay M [16] also noted its association of disability and food insecurity. Food insecurity among vulnerable groups, PLD included, is more rampant in Africa [22].

A proportion did not meet the recommended amount of energy. This results are in line with a study by King, Pomeranz JL \& Merten JW $[19,23]$ and Groce NE, et al. [24] where the study indicated that most of PLD do not meet the RDA for recommended energy. The
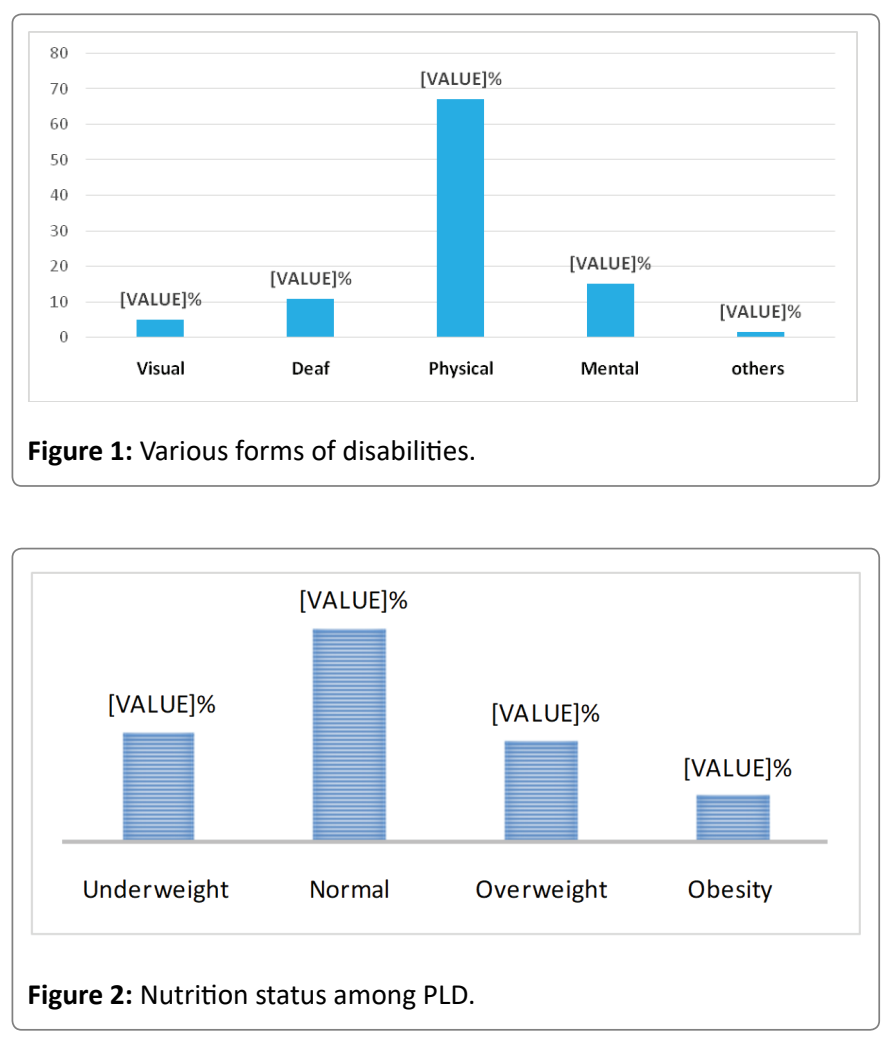
Table 1: Demographic and socio-economic characteristics of PLD.

\begin{tabular}{|c|c|c|c|}
\hline & & \multicolumn{2}{|c|}{ N (396) \% } \\
\hline \multirow{2}{*}{ Sex } & Male & 179 & 45.2 \\
\hline & Females & 217 & 54.8 \\
\hline \multirow{4}{*}{ Age (years) } & $18-29$ & 100 & 25.3 \\
\hline & $30-39$ & 129 & 32.6 \\
\hline & $40-49$ & 107 & 27 \\
\hline & $\geq 50$ & 60 & 15.2 \\
\hline \multirow{5}{*}{ Occupation } & Small business & 207 & 52.3 \\
\hline & None & 111 & 28.1 \\
\hline & Employed & 54 & 13.7 \\
\hline & Casual labor & 14 & 3.5 \\
\hline & Farmer & 9 & 2.3 \\
\hline \multirow{5}{*}{ Income (USD) } & $<100$ & 220 & 55.5 \\
\hline & $101-200$ & 73 & 18.4 \\
\hline & $201-300$ & 50 & 12.5 \\
\hline & $401-500$ & 36 & 9 \\
\hline & $>500$ & 19 & 4.7 \\
\hline
\end{tabular}

Table 2: Dietary diversity score.

\begin{tabular}{|l|c|c|c|}
\hline \multirow{2}{*}{ Dietary diversity score } & \multicolumn{2}{|c|}{ N (396)\% } \\
\hline \multirow{2}{*}{ Energy intake } & <4 food groups & 272 & 68.8 \\
\cline { 2 - 4 } & >4 food groups & 124 & 31.3 \\
\hline \multirow{2}{*}{ < } & <RDAs & 56 & 14.1 \\
\cline { 2 - 4 } & Met RDAs & 183 & 46.1 \\
\cline { 2 - 4 } & >RDAS & 158 & 39.8 \\
\hline
\end{tabular}

Table 3: Relationship between study variables.

\begin{tabular}{|l|c|c|c|}
\hline & Variables & $\mathbf{r}$ & p-value \\
\hline Dietary diversity score & Income & 0.63 & 0.021 \\
\hline & Body mass index & 0.72 & 0.018 \\
\hline
\end{tabular}

high prevalence of overweight, obesity and underweight in line with a study by Van Riper CL [25] who also noted that the two extremes of malnutrition exist among PLD. A world report by FAO [22], indicates current emergence of multiple burden of malnutrition. A study by Martínez-Reig M, et al. [26] in Spain noted that PLD are at a higher risk of poor nutrition status than the normal population. The significant relationship between DDS and nutrition status agrees with Talukder A, et al. [27] who in a study at Bangladesh noted a relationship between DDS and nutrition status.

\section{Conclusion}

The study concludes that due to in ability to secure jobs and challenges in undertaking business ventures, the socio-economic profile of the PLD is low. This translates into food insecurity and poor nutrition status. Overweight and obesity was prevalent. There was also cases of underweight thus the dual burden of malnutrition was noted.

\section{Recommendations}

The study recommends training the PLD on food and nutrition. The County Government should focus on intervention approaches that focus on both underweight and overweight/obese population. In addition, there should be income generating activities to assist PLD in low socio-economic status to boost their income through income generating activities.

\section{Ethical Clearance}

Ethical clearance was obtained from Kenyatta University Ethical Review Committee. Informed consent was sought from the respondents whose confidentiality was assured.

\section{References}

1. World Health Organization (2011) World Report on Disability. WHO, Geneva, Switzerland.

2. An R, Chiu CY, Zhang Z, Burd NA (2015) Nutrient intake among US adults with disabilities. J Hum Nutr Diet 28: 465-475.

3. National Coordinating Agency for Population and Development (2008) Kenya National Survey for Persons with Disabilities (KNSPWD) 2008. Kenya.

4. Snyder LA, Carmichael JS, Blackwell LV, Cleveland JN, Thornton GC (2010) Perceptions of Discrimination and Justice among Employees with Disabilities. Employee Responsibilities and Rights J 22: 5-19.

5. Lawrence D, Kisely S (2010) Inequalities in Healthcare Provision for People with Severe Mental Illness. J Psychopharmacol 24: 61-68.

6. Palmer M (2011) Disability and Poverty: A conceptual Review. J Disabil Policy Stud 21: 210-218.

7. Vick A, Lightman E (2010) Barriers to Employment among Women with Complex Episodic Disabilities. J Disabil Policy Stud 21: 70-80.

8. Emerson E, Baines S (2011) Health Inequalities and People with Learning Disabilities in the UK. Tizard Learning Disability Review 16: 42-48.

9. Onganya DO, Omuya JM, Ombaba KMB, Arogo PA (2012) The Role of Agricultural Growth on Millennium Development Goals in Kenya: A Strategy of Poverty Reduction. J Emerg Trends Econ Manage Sci 3: 324-331.

10. Bjelland $M J$, Bruyère $S M$, Schrader SV, Houtenville AJ, RuizQuintanilla A, et al. (2010) Age and disability employment discrimination: Occupational rehabilitation implications. J Occup Rehabil 20: 456-471.

11. Jones H, Reed R 2003) Water supply and sanitation access and use by physically disabled people. Department for International Development, UK.

12. Schell BAB, Scaffa ME, Gillen G, Cohn ES, Willard HS (2013) Willard \& Spackman's occupational therapy. Lippincott Williams \& Wilkins.

13. Huang DL, Rosenberg DE, Simonovich SD, Belza B (2012) Food Access Patterns and Barriers among Midlife and Older Adults with Mobility Disabilities. J Aging Res 2012: 231489.

14. Brucker DL, Mitra S, Chaitoo N, Mauro J (2015) More likely to be poor whatever the measure: Working-age persons with disabilities in the United States. Soc Sci Q 96: 273-296.

15. Coleman-Jensen A, Nord M (2013) Disability is an important risk factor for food insecurity. United States Department of Agriculture: Economic Research Service, USA. 
16. Quarmby CA, Pillay M (2018) The intersection of disability and food security: Perspectives of health and humanitarian aid workers. Afr J Disabil 7: 1-9.

17. FAO (2018) The State of Food Security \& Nutrition in the World. Rome, Italy.

18. Appunni SS, Blignaut R, Lougue S (2013) Understanding issues of people living with disabilities in South Africa. J Asian Afr Stud 49: 559-569.

19. Jones L, Bellis MA, Wood S, Hughes K, McCoy E, et al. (2012) Prevalence and risk of violence against children with disabilities: a systematic review and meta-analysis of observational studies. The Lancet 380: 899-907.

20. Mugenda OM, Mugenda AG (2003) Research Methods: Quantitative and Qualitative Approaches. Nairobi, Kenya.

21. FAO, Food and Nutrition Technical Assistance (2008) Guidelines for measuring household and individual dietary diversity. Rome, Italy 4: 1-21.

22. FAO, WHO, UNU (2001) Human energy requirements. FAO Food Nutr Tech Rep Ser No 1. Rome, Italy.
23. King JL, Pomeranz JL, Merten JW (2014) Nutrition interventions for people with disabilities: a scoping review. Disabil Health J 7: 157163.

24. Groce NE, Kerac M, Farkas A, Schultink W, Bieler RB (2013) Inclusive nutrition for children and adults with disabilities. Lancet Glob Health 1: e180-e181.

25. Van Riper CL, Wallace LS, American Dietetic Association (2010) Position of the American Dietetic Association: Providing nutrition services for people with developmental disabilities and special health care needs. J Am Diet Assoc 110: 296-307.

26. Martínez-Reig M, Gómez-Arnedo L, Alfonso-Silguero SA, JuncosMartínez G, Romero L, et al. (2014) Nutritional risk, nutritional status and incident disability in older adults. The FRADEA study. J Nutr Health Aging 18: 270-276.

27. Talukder A, Osei AK, Haselow NJ, Kroeun H, Uddin A, et al. (2014) Contribution of Homestead Food Production to Improved Household Food Security and Nutrition Status-Lessons Learned from Bangladesh, Cambodia, Nepal and the Philippines. In: Thompson B, Amoroso L (eds) Improving Diets and Nutrition: Food based Approaches. CABI, UK 58 